\title{
IMPLICAÇÕES NA ESTRATÉGIA DE OPERAÇÕES EM SERVIÇOS DA NORMA NBR 19000
}

$\star$ José Paulo Alves Fusco

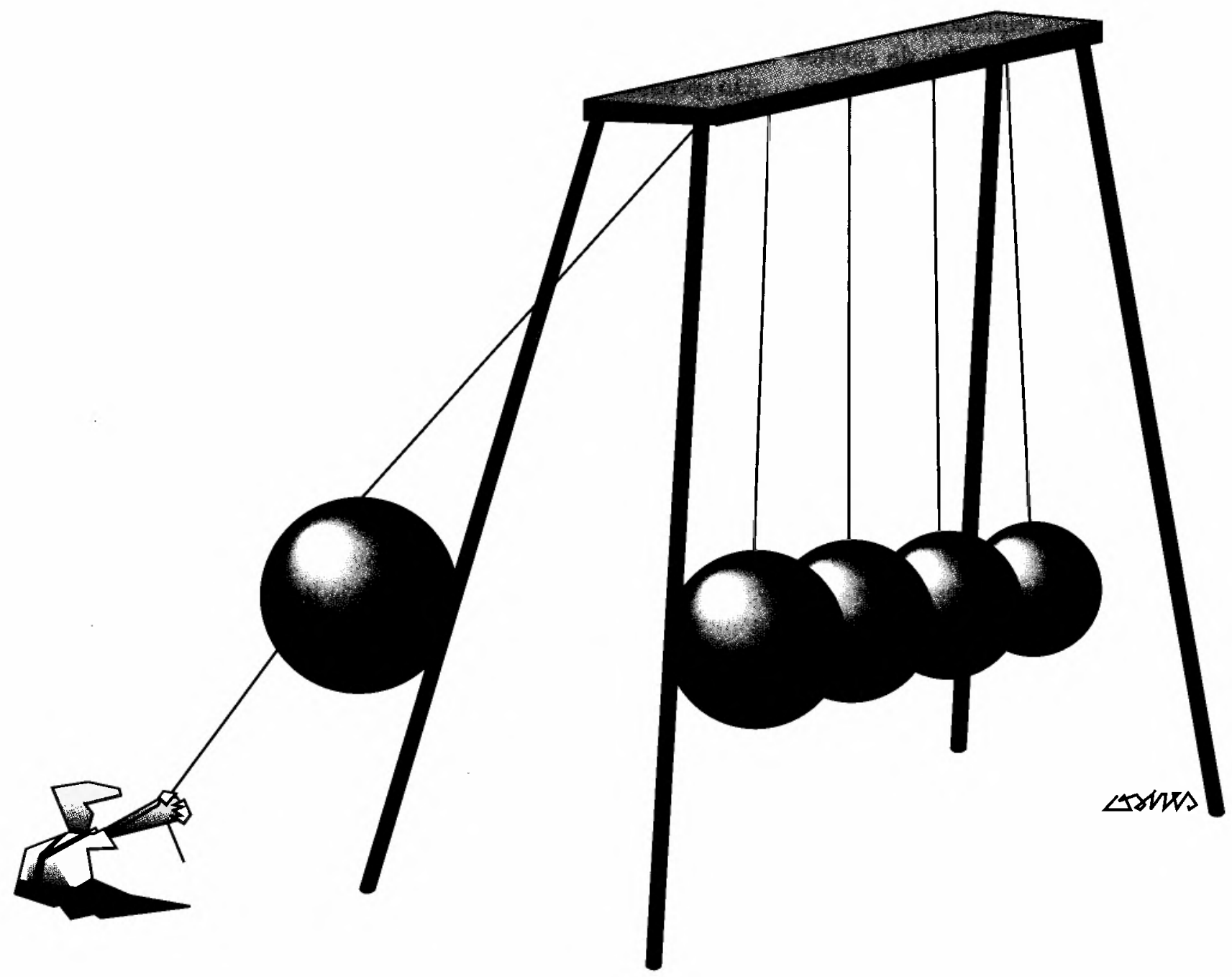

\section{PALAVRAS-CHAVE:}

Estratégia competitiva, NBR ISO 9004-2, sistema da qualidade, competitividade, estratégia de operações de serviços, serviços, metodologia, qualidade, programas de qualidade, administração estratégica, estratégia.

\section{KEY WORDS:}

Competitive strategy, NBR ISO 9004-2, quality system, competitiveness, service operations strategy, services, methodology, quality, quality programs, strategic management, strategy.

\section{$\star$ Engenheiro, Mestre e Doutorando na Escola Politécnica da USP, Consultor de Empresas.}




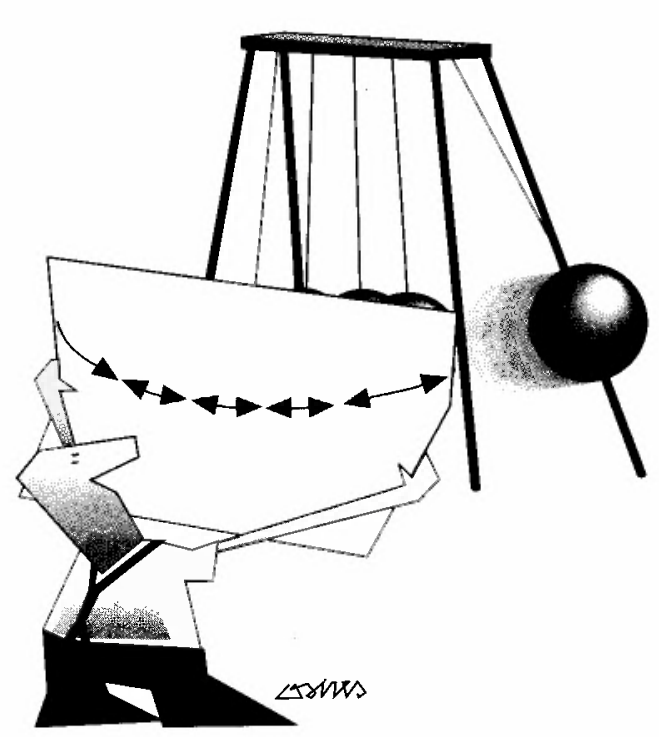

A política de liberalização de mercado adotada pelo governo tem trazido variáveis de contexto concorrencial desconhecidas até há bem pouco tempo.

Hoje, todos estão descobrindo que boa parte de seus rivais no mercado são empresas com sede fora do país. Desse modo, o desenvolvimento de produtos e as estratégias de mercado, devem ser pensados globalmente para enfrentar esse desafio.

Dentro desse cenário tem sido notada uma crescente demanda pelo certificado de conformidade com as normas da série NBR 19000 (ISO 9000), por parte de empresas nacionais dos mais variados ramos de atividade, notadamente de manufatura.

A globalização tornou-se uma realidade atual nesses anos, desde a publicação das normas da série ISO 9000 . Estas, por sua vez, já representam uma realidade e um fator qualificador no mundo dos negócios, no sentido de disciplinar as relaçōes de troca de produtos entre os países e entre empresas.

Em agosto de 1990, o Brasil, a exemplo de vários outros países, também passou a adotá-las, formando a série de normas NBR 19000.

Por meio de vários mecanismos, o governo brasileiro vem fomentando iniciativas visando ao aumento da competitividade nacional como um todo. Algumas importantes empresas estatais vêm exigin- do, já há algum tempo, que seus fornecedores atendam às recomendaçōes das normas, fixando prazos e realizando auditorias. Do mesmo modo, importantes setores da indústria privada têm adotado postura semelhante, porque sabem onde está a chave para o mercado internacional.

Quando pensamos a qualidade em uma perspectiva mais abrangente, consideramos que a série de normas NBR 19000 corresponde ao primeiro grande passo em direção à competitividade, pois traz consigo a necessidade de uma série de mudanças de comportamentos e atitudes.

Ao longo do processo de implantação, são trabalhadas e inseridas importantes variáveis "culturais" dentro da empresa, tais como a necessidade de um constante autoquestionamento, variáveis estas, básicas para a implantação do conceito de "aperfeiçoamento contínuo" (kaizen).

Pragmaticamente, podemos dizer que o certificado de conformidade ISO 9000 atesta formalmente que o seu detentor, além de possuir um sistema de Garantia da Qualidade, segue normas que lhe permite produzir bons produtos em processos estáveis e sob controle.

Embora muito se tenha falado sobre implantação da série de normas NBR 19000 para empresas de manufatura ${ }^{1}$, correspondendo à produção de bens tangíveis, poucos têm se manifestado com relação ao setor de serviços.
1. FUSCO, J.P. A. NBR $19000 x$ manufatura: considerações sobre sua aplicação: vantagens e desvantagens. Revista de $A d-$ ministração de Empresas, v.34, n.4, p.54-63, jul./ago. 1994. 


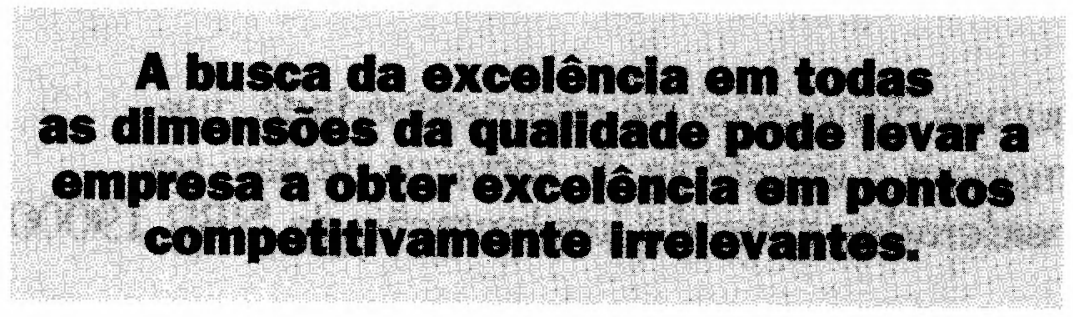

Existe alguma norma para disciplinar as atividades de empresas voltadas à prestação de serviços? Quais as justificativas estratégicas para sua implantação?

Antes de responder a estas e a outras perguntas, é necessário que sejam ponderados todos os fatores que definem a capacidade competitiva das empresas do setor de serviços, as características próprias de seus mercados, o que, afinal de contas, elas vendem, de modo que se conheçam e compreendam todos os fatores críticos envolvidos nesse tipo de atividade e sua sensibilidade, em função da implantação de um sistema de qualidade como o recomendado, contido implicitamente na série NBR 19000.

Este artigo objetiva, fundamentalmente, examinar e apresentar as implicações correspondentes à implementação de procedimentos de conformidade com a norma NBR ISO 9004-2, considerando empresas do setor de serviços, e demonstrando ainda que, à semelhança dos produtos manufaturados, tais implicações vão muito além da simples visão do atendimento a mais um fator qualificador de mercado.

2. GIANESI, I. G. N., CORRÊA H. L. Contributions to service operations strategy development. In: Service Superiority the design and delivery of effective service operations. Warwick: R. Johnston and N.D.C. Slack eds. Operations Management Association, $p$. 13-9.

3. GARVIN, D. A. Competing on the eight dimensions of quality. Harvard Business Review, $\mathrm{p}$ 101-9, Nov./Dec. 1987; What does "Product Quality" really mean? Sloan Mana gement Review, p.25-43, Fall 1984; _. Gerenciando a qualidade: uma visão estratégica e competitiva, Rio de Janeiro: Qualitymark, 1992 . SLACK, N. Vantagem compet $j$ tiva em manufatura. São Paulo: Atlas, 1993.
Já vimos que qualidade é um conceito relativo, e que depende fundamentalmente do cliente-alvo e do potencial que a empresa possui, daquilo que ela é capaz de fazer para atendê-lo.

Alguns autores ${ }^{3}$ trazem-nos, adicionalmente, uma visão pragmática do assunto, no sentido de que a busca da excelência em todas as dimensões da qualidade pode ser uma armadilha, podendo daí advir perda de foco do sistema, levando a empresa a obter excelência em pontos competitivamente irrelevantes. Em outras palavras, recomenda-se que a empresa persiga objetivos que lhe permitam ser melhor do que seus concorrentes em tudo aquilo que for importante.

Desse modo, é importante ponderar todas as variáveis concorrenciais no contexto dos negócios da empresa, considerar o potencial próprio, representado pela estrutura de seu sistema de operações, plantas, equipamentos e pessoas, bem como sua infra-estrutura ou sistemas de gestão. Como resultado, a empresa poderá ter claramente colocados os seus fatores críticos de sucesso, ou seja, os fatores que devem ser privilegiados porque contribuem fortemente para $o$ atingimento de uma posição concorrencial destacada, além de seus objetivos de qualidade, estabelecidos em função disso.

Conseqüentemente, a discussão resume-se a uma reflexão sobre os objetivos do sistema de operações de serviços, obtidos em virtude da realidade concorrencial da empresa, e considerando, finalmente, os objetivos de qualidade como sendo aqueles que contribuem direta e fortemente para sustentar aqueles primeiros.

\section{A qualidade como fator estratégico}

Configurando um importante paradigma competitivo atual, o cliente deve ser visto como o ponto-chave de um sistema de operações. A sua satisfação somente será atingida por meio da harmonização dos relacionamentos existentes entre os fatores de produção, processos operacionais e pessoas envolvidas.

É importante colocar que qualidade é um conceito que faz sentido quando definido comparativamente - em relação aos 
concorrentes - e não quando em relação a padrões fixos, internos, reconhecendo que os clientes dão a última palavra na determinação da aceitabilidade ou não de um produto.

Em face disso, o atendimento às especificaçōes passou a ter uma ênfase gerencial menor, fazendo sentido somente após uma cuidadosa definição das necessidades dos usuários.

$A$ pesquisa de mercado para a avaliação da qualidade passa a cumprir um papel importante no jogo, sem a qual as empresas năo conseguem saber como posicionar seus produtos com base na Qualidade. O que é qualidade para meus clientes? Considerando a visão final do acionista ou controlador da empresa, o que significa qualidade em termos de retorno de investimentos?

Pesquisas confirmam o impacto da Qualidade nos níveis mínimos de retorno. Para Buzzel c Gale+, por exemplo, os estudos do Impacto sobre o Lucro das Estratégias de Marketing (Profit Impact of Marketing Strategies - PIMS), mostraram nāo só que empresas cujos produtos eram de qualidade superior tinham um retorno maior sobre o investimento (ROI) e sobre vendas (ROS) (ver figura 1).

Adicionalmente, as pesquisas demonstraram que tal ocorria qualquer que fosse a participação no mercado, além do que tais fatos ocorriam associados a ganhos de participaçâo no mercadō̄.

Esta constataçăo forneceu os elementos e trouxe, finalmente, a certeza de que a melhoria da Qualidade poderia ser uma meta rentável ${ }^{(0)}$

Utilizando uma "ponte" com sistemas de manufatura, um exame do lado da produção também apontava nesta direçâo. Há muito tempo sâo conhecidos e tratados os custos da Qualidade, mas só recentemente foi "descoberta" (ou comprovada com fatos) a existência concreta de uma correlação posiliva entre Qualidade e Produtividade.

É mais ou menos óbvio que um processo de fabricação sem defeitos (e isto vale também para produção de serviços) resulta em produto mais eficiente do que outro que scja sempre interrompido para "retraba- lhos" e para reparos ${ }^{7}$. A utilização dos recursos de produção será provavelmente maior, os estoques tenderão a diminuir e a mão-de-obra tenderá a ser mais produtiva.

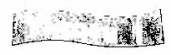

QUALIDADE RELATIVA X TAXAS DE RETORNO (ROI e ROS)

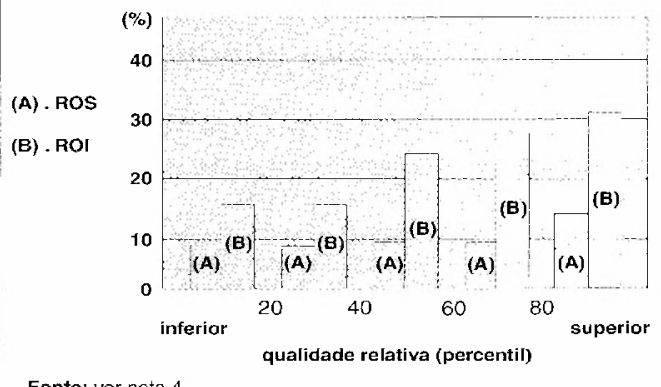

Fonte: ver nota 4

Provada a relação entre Qualidade e retorno de investimentos, ou aumento de rentabilidade, năo resta mais razão para hesitações. Diante disso, um número cada vez maior de empresas tem constatado que a Qualidade representa de fato uma poderosa arma concorrencial, oferecendo grandes benefícios, tanto do lado do mercado (concorrência) como do lado do custo (resultado da eficiência técnica).

Cada vez mais, o uso de sistemas estruturados de garantia de qualidade passa a ser uma condição qualificadora de mercado, podendo significar uma vantagem real na disputa pelos melhores e mais rentáveis segmentos.

Em função da dinâmica efervescente em que evolui o contexto concorrencial em geral, as metas de Qualidade passam a ser alvos móveis, passíveis de reformulação contínua, em níveis cada vez mais altos.

Antes de considerar Qualidade como um desideratum, ć preciso haver uma compreensão mais ampla de sua conceituação, para a obtenção de todos os benefícios, explorando todas as possibilidades envolvidas.

Muitos exemplos frustrados de implantação de programas de Qualidade têm revclado que, embora quase todos tenham conseguido muita eficiência em treinamento das técnicas de Controle da Qualidade, em geral têm deixado a descjar
4. BUZZELL, R. D., GALE, B. T. PIMS - O impacto das estratégias de mercado no resultado das cmpresas. São Paulo: Pioneira, 1991.

5. Ver também SCHOEFFLER, S. et al. Impact of strategic planning on profits perfomance, Harvard Business Review. p.137-45, Mar./April 1974; BUZZELL, R. D. WIERSEMA, F. Succesful share-building strategies, Harvard Business Review, p. 135-44. Jan./Feb. 1981.; DEMING W. E Quality. productivity and competitive position, Massachussetts: Cambridge - Center for Advanced Engineering Study, 1982: FEIGENBAUM, A. V. Quality and productivity, Quality Progress, p 18-21, Nov. 1977.

6. Ao falar-se genericamente de "cliente", na realidade está sendo considerado implicitamente algumas definiçoes a priori: dentro de uma dada unidade estratégica de negócios; visando um segmento de mercado com características socioeconômicas bastante conhecidas; visando atendimento às pessoas ou clientes finais, típicos de um segmento de mercado definido.

7. GARVIN, D. A. Gerenciando a qualidade... 0p. Cit. 


\section{QUADERO 1}

\begin{tabular}{|c|c|}
\hline Fatores de mercado & Medidas \\
\hline Crescimento do mercado & - Taxa média de variação do real do mercado \\
\hline Estágio de evolução do mercado & $\begin{array}{l}\text { - Idade do produto ou serviço } \\
\text { - Estágio no cicio de vida }\end{array}$ \\
\hline Inflação & - Taxa média de variação de preços \\
\hline Sindicalizaçăo & - \% de empregados sindicalizados \\
\hline Concorrência de prociutos importados & $\begin{array}{l}\text { - Importaçōes a exportaçōes, como \% das } \\
\text { vendas do selor }\end{array}$ \\
\hline Fornecedores & - \% compras dos 3 malores fornecedores \\
\hline Padronizaçāo de produtos e serviços & $\begin{array}{l}\text { - Padronização x personalizaçäio de } \\
\text { produtos e serviços }\end{array}$ \\
\hline $\begin{array}{l}\text { Importância dos produtos para os } \\
\text { clientes }\end{array}$ & $\begin{array}{l}\text { - Magnitude da operaçãa tipica } \\
\text { - Compras na classe de produtos como \% } \\
\text { das compras totais do cliente }\end{array}$ \\
\hline
\end{tabular}

\section{QUADDRO 2}

\section{DIMENSŌES IMPORTANTES PARA POSIÇÃO COMPETITIVA}

\begin{tabular}{|c|c|}
\hline Elementos de posição & Medidas de posição \\
\hline Posição competitiva & $\begin{array}{l}\text { - Participação da UEN (Unidade Estratégica } \\
\text { de Negócios) no Mercado Servido - MS } \\
\text { - Posição relativa da participaçāo da } \\
\text { mercado da UEN }\end{array}$ \\
\hline $\begin{array}{l}\text { Polfiticas quanto a produtes } \\
\text { e serviços }\end{array}$ & $\begin{array}{l}\text { - Índice da qualidade relativa } \\
\text { - Novos produtos ou serviços como \% } \\
\text { das vendas e face a concorrentes }\end{array}$ \\
\hline Preços & $\begin{array}{l}\text { - Indice relativo de preços da UFN } \\
\text { (média dos concorrentes }=100 \text { ) }\end{array}$ \\
\hline Programas de marketing & - \% das vendas \\
\hline Estratégias de investimento & $\begin{array}{l}\text { - Valor do ativo imobilizado sobre vendas, } \\
\text { valor agregado } \\
\text { - Idade do Al(ativo imobilizado) } \\
\text { - Produtividade da M.O. (māo-de-obra) } \\
\text { - Estoque (\%) sobre vendas }\end{array}$ \\
\hline Integraçāo vertical & $\begin{array}{l}\text { - Valor agregado (\% sobre vendas) } \\
\text { - Em relaça aos concorrentes }\end{array}$ \\
\hline Pesquisa e desenvolvimento & $\begin{array}{l}\text { - Despesas de P\&D - Pesquisa e } \\
\text { Desenvolvimento ( } \% \text { sobre vendas) }\end{array}$ \\
\hline
\end{tabular}

8. LEVY, A.R. Competitividade organizacional: decisōes empresariais para uma nova ordem econômica mundial, São Paulo:Makron, McGraw-Hill, 1992.
Quando se pensa em implantação de procedimentos de conformidade com a norma NBR ISO 9004-2, notadamente em. atividades de alto contato, como em empresas do setor de serviços, normalmente as pessoas pensam apenas na dimensão mercadológica, no atendimento a uma condicionante (qualificadora) concorrencial de mercado, esquecendo-se de um. ponto muito importante: como a internalização dos procedimentos correspondentes à conformidade corn a norma pode atuar como alavanca da capacidade do sistema de operações, no suporte à estratégia competitiva da empresa.

\section{CONSIDERACÕES SOBRE ESTRATÉGIA DE OPERAÇṌES}

\section{Estratégia global $x$ estratégia de operaçóes}

A estratégia de um negócio é uma configuração que procura articular decisóes referentes aos fatores de produçāo, que convertem os recursos em produtos e/ou serviços, com decisões correspondentes ao atendimento dos fatores concorrenciais de atendimento aos mercados servidos.

Algumas variáveis, de caráter mais conjuntural, estarăo mais longe do raio de ação da empresa, envolvendo basicamente medidas de fatores de mercado e setoriais (ver quadro 1).

Outras variáveis estarão mais diretamente envolvidas e no raio de ação de uma empresa, notadamente aquelas que permitem à empresa aferir medidas de posição competitiva e estratégica (ver quadro 2). Estas sāo as variáveis que devem ser utilizadas no Benchmarking com a concorrência ("ser melhor do que a concorrência em tudo o que importa").

Levy ${ }^{8}$ coloca o processo de obtenção da estratégia de uma empresa como sendo o resultado da ponderação de duas grandes dimensões. A primeira, a dimensão de conversão, que significa a transformação de recursos em produtos, englobando aí, portanto, todos os processos produtivos e de logística, e envolvendo desde os recursos ou fatores de produçāo até os produtos finais. A segunda, a dimensāo de posicionamento, que envolve uma discussão e decisão completa sobre o negócio, ou 
seja, de decidir o conceito do negócio.

Essa colocaçăo de levy é interessante porque propōe um modelo estruturado e sistematizado para analisar uma empresa. É, no enlanto, importante que façamos aqui algumas consideraçōes, procurando trazer alguns de seus conceitos para o desenvolvimento da abordagem metodoló gica que estamos procurando.

O conceito de FCS (Fatores Críticos de Sucesso), para um negócio de modo geral, pode enlão ser decomposto em fatores de conversão, que representam os pontos sobre quais a empresa deverá perseguir a cxcolência, via uma estratégia de operações adcquada, além de fatores de posicionamenlo, que representam os pontos em que a empresa deverá perscguir a cxcelência via uma estratégia adequada para ligar suas operaçōes ao mercado servido.

A análiso de conversão deve iniciar-se com uma análise da situaçâo da empresa em cada um dos recursos-chave, cm comparaçáo às empresas concorrentes. O passo seguinte é determinar como deve ser a situação de cada um dos tipos de recursos, ou fatores de conversão, dados os requisitos da estratégia.

Normalmente, um número reduzido de recursos envolvidos na função de conversão deve ser considerado como de fatores críticos, com o fim de facilitar as operaçóes de uma empresa, de modo a lhe possibilitar o alcance dos objetivos traçados preliminarmente em sua estratégia.

Uma empresa deve perseguir, portanto, dois importantes desafios básicos: satisfazer melhor os clientes e ser melhor do que a concorrência.

Isto implica trazer para dentro da fábrica a visão dos clientes, com os aspectos da competitividade que são importantes para eles, além da visão dos concorrentes, ou seja, a medida contra a qual o seu próprio desempenho será julgado.

Slack ${ }^{9}$ propōe um modelo para sistemas de manufatura composto por basicamente cinco dimensōes (ver figura 2), ou seja, qualidade, velocidade de fluxo, confiabi-

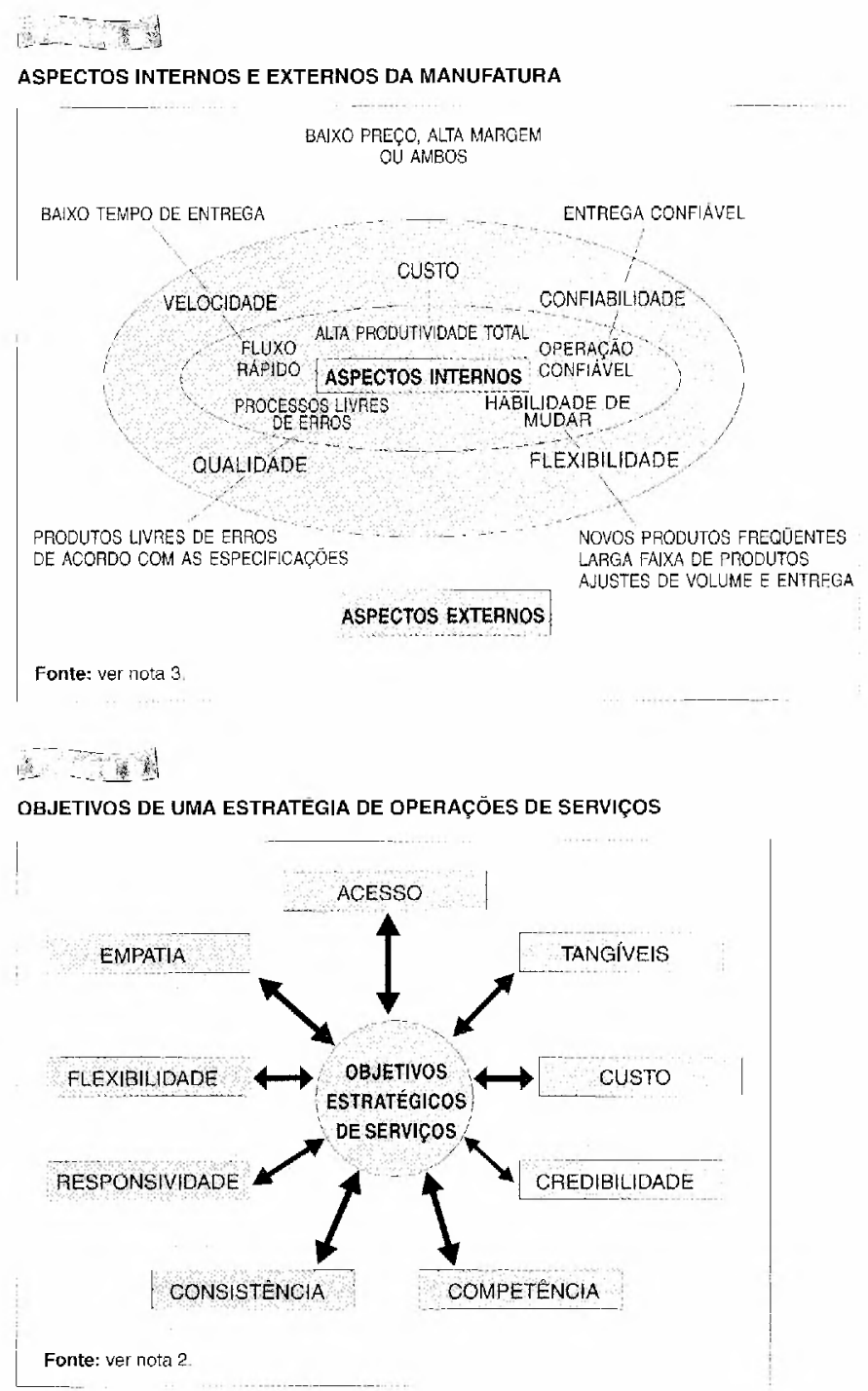

lidade de entrega, flexibilidade e custo. Diferentes autores, como Bolwijin e Kumpe, e Brunstein ${ }^{10}$, apresentam outros conjuntos de performance criteria, que consideram a inovação como sendo uma dimensão adicional de competitividade, mas, aí, já englobando o negócio como um todo e não apenas o sistema de manufatura.

Seu objetivo era fornecer um contexto analítico para, dentro de qualquer sistema de manufatura, avaliar sua performance segundo os cinco grandes objetivos (ou dimensōes) e determinar os caminhos a seguir, considerando os inevitáveis trade-offs envolvidos e reconhecendo que melhorias ou ênfase em um aspecto acabam sendo "pagas", com algum sacrifício de desempenho, em outros ${ }^{11}$.

No entanto, quando consideramos ope-
9. SLACK, N. Op. Cit.

10. BOLWIJN, P. T, KUMPE, T. Manufacturing in the 1990's: productivity, flexibility and innovation. Long Planning, v. 23 , n.4, p.44-57, 1990; BRUNSTEIN, I. Avaliaçäo e perspectivas da área de engenharia de produção. In: ENENGEP - ENCONTRO NACIONAL DE ENGENHARIA DE PRODUCÃO. Anais. João Pessoa: ABREPRO,1994.

11. SKINNER, W. Manufacturing: missing link in corporate strategy. In: GARVIN. D., Operations strategy: text and cases. Englewood Cliffs: Prentice Hall, 1992. 


\section{Alevia 4}

INFLUÊNCIA DIRETA E INDIRETA DA NBR ISO 9004-2 SOBRE AS DIMENSÖES COMPETITIVAS DE OPERAÇŌES DE SERVIÇOS

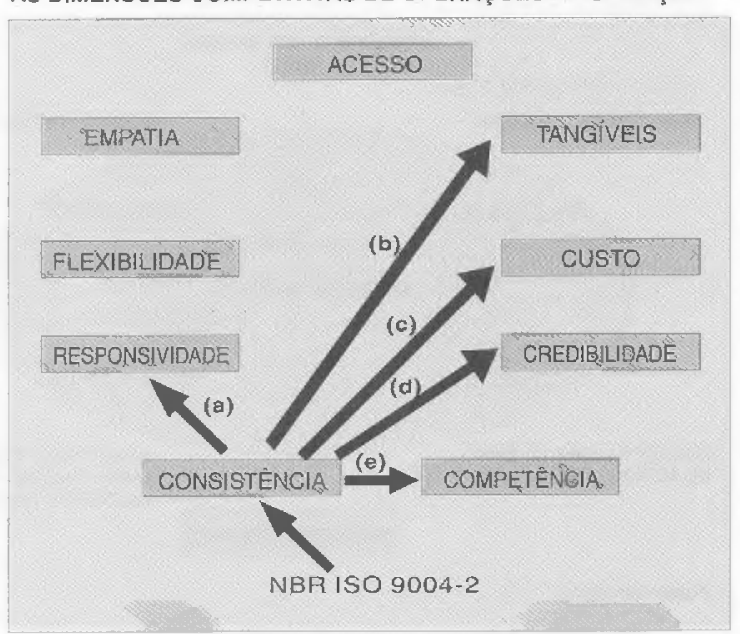

raçōes de serviços, cuja característica principal é desenvolver atividades de alto contato, com maior grau de participação dos clientes na "produçāo do serviço", outros aspectos devem ser levados em conta em função dos critérios mais complexos e subjetivos de avaliação utilizados pelos clientes.

Vários autores têm discutido e apresentado critérios de perfomance para análise de operaçōes de serviço. Gianesi e Corrêa ${ }^{12}$ sugerem um modelo de critérios competitivos, o qual, por ser bastante abrangente, será utilizado para efeito deste trabalho (ver figura 3).

\section{NORMA NBR ISO 9004-2 x OPERACÕES DE SERVIÇOS}

A implantação de um sistema de garantia da Qualidade, como o sugerido pela norma NBR ISO 9004-2, influencia o desempenho de uma empresa, segundo (ou por meio de) alguns dos objetivos estratégicos de operaçōes de serviços propostos por Gianesi e Corrêa ${ }^{13}$, uns em maior grau do que outros.

A aplicação dos postulados da norma ao ambiente do sistema de operação de serviços possibilita obter:

12. GIANESI, I. G. N., CORRÊA, H. L. Op. cit.

13. Idem, ibidem
- maior conformidade dos serviços quanto às especificações para a sua obtenção e performance;
- maior consistência na obtenção dessa conformidade;

- menores níveis de perdas internas ao sistema de operaçōes;

- maior consistência das variáveis inerentes ao seu processo de obtenção;

- maior conformidade entre as especificaçôes de obtenção dos serviços em relaçāo ao seu projeto;

- maior eficiência na utilizaçāo dos recursos produtivos;

- melhor nivel de conhecimento dos processos do sistema de operações, por parte do pessoal envolvido;

- menores tempos improdutivos;

- menores níveis de custo operacional do sistema.

A figura 4 ilustra o relacionamento direto da aplicação da norma NBR ISO $9004-$ 2 com o objetivo de consistência bem como seus desdobramentos em relação aos demais objetivos estratégicos de operaçōes de serviços.

A influência da norma NBR ISO 9004-2 traduzir-se-ia, assim, basicamente nestes resultados:

- maior responsividade, ou menores tempos de respusta às solicitaçũes dos clientes, como resultado da eliminação de tempos "mortos" no sistema, por meio de níveis menores de "não-conformidades", decorrência do maior aprendizado por parte dos envolvidos no processo. Desse modo, ganhos no tempo de obtenção dos serviços podem significar serviços mais rapidamente prestados, liberando o sistema para atendimento a maior número de clientes;

- operaçōes de serviços tangíveis, por meio da qualidade percebida pelos clientes com relação à adequação dos instrumentos operacionais utilizados, instalaçóes, equipamentos, qualificação do pessoal envolvido;

- custos menores na obtenção e prestação dos serviços, uma vez que possibilita operar com menores níveis de tempos "mortos", além de menores custos com relação à correção a posteriori de "nãoconformidades" nos serviços prestados. 
Como resultado da relaçāo direta entre Qualidade e produtividade, segundo o modelo proposto por Gold ${ }^{14}$, a figura 5 sugere que a conformidade com a norma NBR ISO 9004-2 pode significar ganhos substanciais.

Resumidamente, como mostrado nessa figura, temos:

aumento da relação Lucro/Saídas, como resultado da diminuição do custo médio operacional do sistema, à medida que a empresa passa a trabalhar com níveis superiores de eficiência na utilizaçấo de recursos;

aumento da relação Saídas/Investimento Total, como resultado da elevação do nível de utilização da capacidade instalada, para obtenção de serviços em conformidade com o solicitado pelos clientes;

maior credibilidade e segurança, como resultado da prestação uniforme e consistente dos serviços e, ainda, confiabilidade nos resultados;

maior competência do pessoal envolvido na produção e prestação dos serviços, como resultado de um conhecimento mais profundo do sistema de operaçóes, obtido como um subproduto da padronizaçăo dos processos e maior facilidade de treinamento daí resultante.

Ainda com relação à qualidade, podemos utilizar a classificação adotada por Garvin'", que define oito dimensōes para análise e ação gerencial, considerando aí a qualidade inerente ao produto. Podemos generalizar este conceito para envolver também operações de serviços.

A figura 6 fornece um quadro correspondente às influências diretas e indiretas da implementação de procedimentos em conformidade com a norma NBR ISO 9004-2, nas dimensões da Qualidade dos produtos $^{16}$.

Se observarmos os modelos propostos por Garvin ${ }^{17}$ - mediante alguma abstração e transferindo os conceitos colocados, de dimensões de qualidade, para serviços
O MODELO DE

O MODELO DE RELAÇÕES DE PRODUTIVIDADE

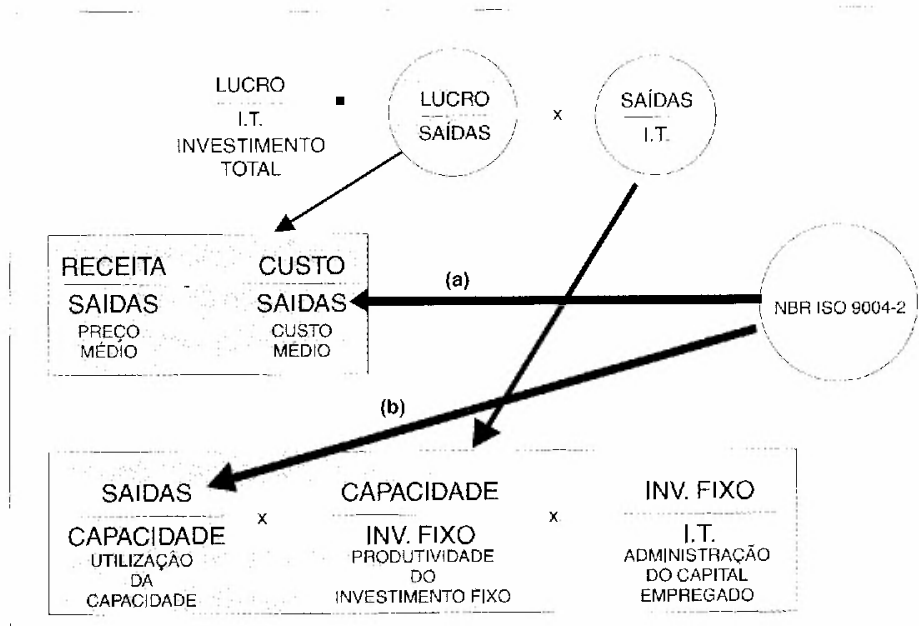

Fonte: ver nota 13

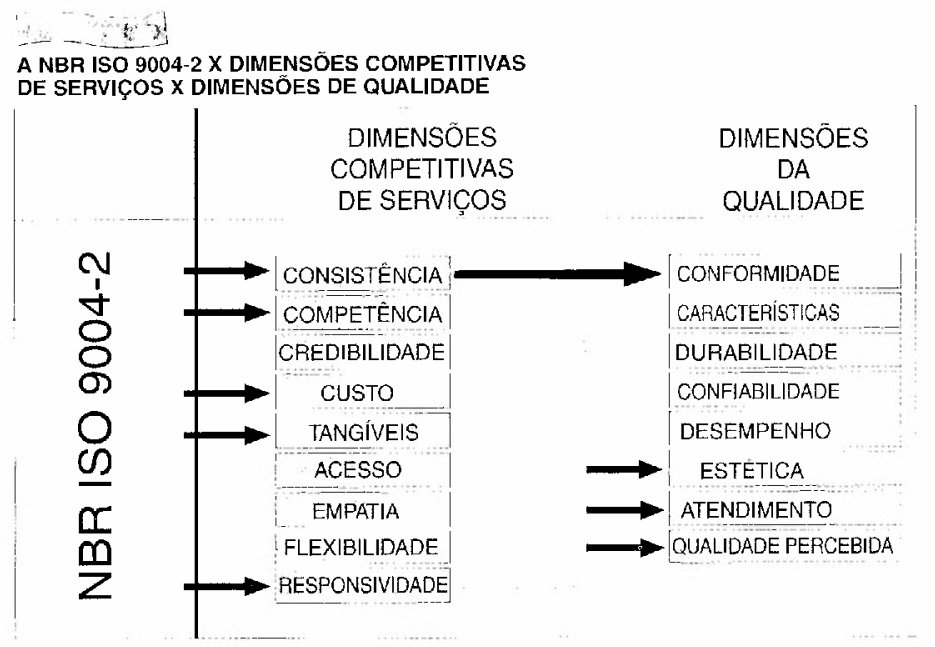

-, os objetivos estratégicos de operaçóes de serviços apresentados por Gianesi e Corrêa ${ }^{18}$, além dos pressupostos contidos na série NBR ISO 9004-2, fica claro não só a complementaridade das definições ali contidas, mas também que todos eles correspondem, sob um prisma diferente, às mesmas idéias.

Portanto, analogamente ao que se afirma para as operações de manufatura, podemos considerar duas grandes dimensôes de resultado para justificar a adoção de procedimentos $\mathrm{em}$ conformidade com a norma NBR ISO 9004-2:

dimensão de mercado (variáveis externas), para manter ou conquistar a con-
14. GOLD, B. Technology, productivity and economic analysis, The International Journal of Management Sciences, v. 1 , n.1, 1973

15. GARVIN, D. A. Competing on the eight dimensions... Op. Cit.: What does "Product Quality"... Op . cit.; Gerenciando a qualidade... $\overline{\mathrm{Op}}$ Cit.

16. Idem, ibidem.

17. Idem, ibidem

18. GIANESI, I. G. N., CORREAA H. L. Op. cit. 
fiança de parceiros em negócios, superar barreiras comerciais, ou mesmo formar ou recuperar uma imagem positiva;

- dimensão de eficiência técnica (variáveis internas), para:

- privilegiar a produtividade no uso dos fatores de produção;

- assegurar conformidade do serviço em relação ao que foi especificado;

- assegurar que o serviço ocorra com um desempenho adequado ou em conformidade com o que foi projetado, em termos de atendimento ao cliente como um todo;

- assegurar consistência na obtenção da confiabilidade do resultado dos serviços prestados;

- assegurar consistência na confiabilidade dos processos utilizados para "geração dos serviços";

- assegurar, com fornecedores, relacionamento adequado, formal e conhecido;

- assegurar condições para aperfeiçoamento contínuo, mediante procedimentos de rastreabilidade e identificação das eventuais "năo-conformidades" em todas as fases do processo de obtenção do serviço;

- assegurar a adoção de procedimentos para implementação de ações corretivas que possibilitem evitar a recorrência de problemas de qualidade.
No entanto, fica mais ou menos evidente que a implantaçāo isolada da norma NBR ISO 9004-2 não significa uma solução mágica que vai resolver todos os problemas. Podemos afirmar que existem vários outros aspectos estratégicos ligados ao desempenho do sistema de operações de serviços, que nāo são impactados pela implantaçāo da NBR ISO 9004-2.

Considerando as dimensöes de competitividade colocadas para estratégia de operaçōes de serviços, em função do tipo de negócio explorado pela empresa, podemos afirmar que pode ou năo ser vital a adoção da NBR ISO 9004-2, uma vez que nem todas as dimensões de competitividade são afetadas.

Independente de ser uma empresa de manufatura ou serviços, retiradas as evidentes implicações ou razōes de mercado envolvidas, a adoçāo da norma NBR ISO 9004-2 pode ser encarada como um primeiro passo mais pragmático (à medida que possibilita resultados a curto e médio prazos) para implantaçāo de um programa de ação competitiva global em uma empresa.

Além disso, como normalmente seus resultados costumam ser práticos, palpáveis e facilmente visíveis a curto prazo, a implantação da norma pode ser pensada como sendo uma "cunha de penetração" para viabilizar a implantação do conceito de Qualidade segundo uma perspectiva mais abrangente.

\section{BIBLOOMRAFIA SUPLEMENTAR}

ASSOCIACĀO BRASILEIRA DE NORMAS AÉCNICAS. Normas de gestão da Qualidade e garantia da Qualidade: diretrizes para seleção e uso, NBR' 19000. Rio de Janeirö: ABNT, 1990.

Gestão da Qualidadę e elementos do sistẻma da Qulualidade: diretrizes para serviços, NBR ISO-9004-2. Rio de Janeiro: ABNT, 1993.

GROSBY P. B. Qualidade: falando șếrio. São Paulo: McGraw-Hill, 1990

HAYES, R., WHEELWRIGHT, S.C. Restoring out competitive edge. New Yark:Wiley, 1984.

Competing through manutacturing. In: GARWN, D. Operations strategy: text and cases, Englewood Cliffs: Prentice-Hall, 1992

17. MUSCAT, A.R.N. Occonceito de produtividade. São Paulo: Escola Politéenica da USP, 1990. (Papen) 